\title{
A IDENTIFICAÇÃO NACIONAL NOS ELEMENTOS DE O GRANDE DESFILE
}

\author{
Christiane Aparecida Tragante ${ }^{1}$
}

\section{Resumo}

O presente trabalho tem a pretensão de estabelecer um diálogo dos elementos utilizados na obra do artista Nelson Leirner com os índices que valorizam a unidade do Brasil no nacionalismo, dando ênfase às reflexões sobre a origem de tais elementos e o desenvolvimento da nação brasileira, caminhando com a obra do artista ao contexto da contemporaneidade e meditando acerca do papel exercido por tais obras enquanto mantedoras ou questionadoras da identidade brasileira.

Palavras-Chave: arte; crítica de arte; nacionalismo; Leirner; nação.

\section{Resumen}

El presente trabajo tiene la pretensión de establecer un diálogo de los elementos utilizados en la obra del artista Nelson Leirner con los índices que valoran la unidad de Brasil en el nacionalismo, dando énfasis a las reflexiones sobre el origen de tales elementos y el desarrollo de la nación brasileña, caminado con la obra del artista al contexto de la contemporaneidad y meditando acerca del papel ejercido por tales obras como mantenedoras o cuestionadoras de la identidad brasileña.

Palabras Clave: Arte; crítica de arte; nacionalismo; Leirner; nación.

Em meio ao contexto da globalização, as reflexões formuladas em torno da idéia de identidade e que remetem à questão cultural não cessam de surgir. A causa de tal fenômeno se dá pelo fato da globalização evocar um juízo de quebra de fronteiras e unidade mundial, abalando as estruturas sociais e, conseqüentemente, modificando as identidades. Os teóricos das ciências sociais levantam possíveis conseqüências, no que concerne as identidades, vistas na esfera da internacionalização, que vão desde a sua desintegração devido à unidade cultural ao seu fortalecimento como opção de resistência à nova conjuntura.

A noção de identidade é vista como um conceito, dentro das ciências sociais, polissêmico e fluido, dando lugar às várias re-interpretações e definições. Num âmbito maior, podemos dizer que ela é aquela que vincula o sujeito a uma referência social, como raça, idade, sexo, de modo que ele possa se localizar dentro do sistema e ser localizado. A identidade social, desta forma, é concomitantemente uma maneira de identificar e também de diferenciar, inclusiva e exclusiva, já que une aqueles que têm algo em comum e os diferencia dos outros.

A diferenciação entre cultura e identidade se dá pelo fato de ser a cultura algo que acontece sem que se exista a consciência de identidade, enquanto a identidade pode estar carregada de questões ideológicas. É importante que se tenha claro que a noção de identidade não é algo definitivo dentro do contexto social, não é imutável, mas sim relacional. Ela é uma construção social e não um dado e para tal, é construída por agentes que determinam escolhas e orientam suas representações, dentro de um contexto. É

1 Programa de Pós-Graduação de Arquitetura e Urbanismo da Escola de Engenharia de São Carlos da Universidade de São Paulo. 
mutável, pois se constrói e se reconstrói no interior das trocas sociais, apresentando-se como algo inconstante (CUCHE, 1999, p.176).

O conceito de identidade nacional dá-se seguindo as mesmas condições que foram acima colocadas. Assim, a identidade nacional também agrupa os sujeitos segundo algo comum a eles, o ser brasileiro une toda a população do país que se identifica ligando-se por fatores comuns, como a língua, a cultura, as tradições históricas, dentre outros, mantendo uma identidade interna ao Brasil e uma alteridade referente aos outros paises.

É claro, porém, que um país com as dimensões do Brasil, não pode ser único nas suas manifestações culturais de maneira que há razões para se questionar os critérios que identificam os brasileiros, perguntando-se de qual lugar eles são provenientes, ou ainda, desvendando a maneira como a identidade nacional foi e vem sendo considerada.

No âmbito da identidade nacional, surge a obra do artista Nelson Leirner que, através da apropriação de objetos industrializados ou artesanais retirados da cultura de massa, realiza instalações com elementos que demonstram certa identidade com o Brasil. São eles enfeites, adornos, brinquedos infantis, imagens religiosas e uma porção de elementos que tem características nacionais e que nos levam a indagação do porquê tais elementos representarem o Brasil. Para que seja que possamos, portanto, deslindar este assunto é preciso um breve histórico sobre a identidade nacional no Brasil.

A construção de uma identidade nacional no Brasil é um debate tão antigo quanto heterogêneo, abarcando intelectuais que atribuíram aos mais diversos conceitos o papel unificador dos brasileiros. Para se compreender o conceito de identidade nacional, devemos entender anteriormente que ele está intimamente ligado ao processo de construção de um Estado-nação.

Segundo Marilena Chauí (2000), a historia da nação é uma invenção recente e foi inserida no contexto político brasileiro, como referente a Estado-nação, por volta de 1830. Após o surgimento do conceito de nação na política, segundo Eric Hobsbawm no pensamento de Chauí, podemos definir três etapas do nacionalismo: de 1830 a 1880 - falase em princípio de nacionalidade, vinculando a nação ao território e no qual o Brasil se define como um país essencialmente agrário; de 1880 a 1918 - a idéia nacional ou o caráter nacional atribuem o papel unificador à língua, à religiosidade e à raça; e de 1918 a 1950-60 - a questão nacional ou identidade nacional inclui um conjunto de lealdades políticas assumidas através de intervenções estatais.

O surgimento do Estado moderno levou à construção da nação por objetivos estritamente ideológicos. Uma vez que esse Estado era definido através de seu território e que as ações políticas e administrativas já existiam, faltava-lhe a união e a lealdade dos cidadãos para o consentimento das políticas fiscais e ações militares. E, para tal, a idéia de nação vai sendo construída como solução dos problemas apresentados. Destarte, o que inicialmente constituía-se o principio de nacionalidade, ou seja, a questão territorial, não era o suficiente para que os cidadãos fossem aliados ao Estado, visto que este disputava a fidelidade com as lutas sociais e a religiosidade, era necessário que houvesse uma religião cívica que traria os fiéis contíguos ao Estado, e o que constituía o patriotismo, através da religião cívica veio a ser o nacionalismo do período de 1880-1918 (Idem. p. 17-18).

Vários foram os critérios que definiram a nacionalidade, no final do século XIX e início do século XX, teóricos tentaram encontrar nas idéias evolucionistas e no positivismo, um caminho para se compreender o atraso no país e, para tal, duas noções atuaram: o meio e a raça, explicando a apatia do mameluco, a sexualidade do mulato, a indolência, o nervosismo entre outros. Na virada do século, o papel unificador da nação será imposto ao 
mestiço. O mito das três raças demonstra que o Brasil é composto por negros, índios e brancos e a miscigenação leva ao elemento identificador possibilitando a todos se reconhecerem como nacionais. Desta maneira, depois de ser re-elaborada, a ideologia da mestiçagem:

Pôde difundir-se socialmente e se tornar senso comum, ritualmente celebrado nas relações do cotidiano, ou nos grandes eventos como o carnaval e o futebol. $\mathrm{O}$ que era mestiço torna-se nacional (ORTIZ, 1985, p. 41).

No período que abrange os anos 20-30 e o Estado Novo, a idéia de nacionalismo como compreendida no caráter nacional tomou formas mais agudas e através dos meios de comunicação de massa, os nacionalistas puderem inserir no cotidiano da população os símbolos nacionais. Na década de 50 com a criação do ISEB - Instituto Superior de Estudos Brasileiros, a identidade nacional é firmada a partir de uma tentativa do ideal de desenvolvimento econômico que tinha como fim a autonomia nacional, de acordo com o modelo americano de potência autônoma. Aos CPCs - Centros Populares de Cultura, criados na década de 60, cabia a conscientização das massas que seria feita pela burguesia nacional progressista e as massas conscientes, visando o combate ao imperialismo e o conseqüente ser brasileiro.

Com a instituição do CFC - Conselho Federal de Cultura, em 1966, fica claro a preocupação em se pensar a questão cultural em termos nacionais. O discurso cultural dos representantes do CFC é definido através da ideologia de um Brasil mestiço que, visto sob o conceito de heterogeneidade, ficou estabelecido o papel que unificaria o nacional em tal contexto: a idéia de um Brasil heterogêneo, unificando a diversidade cultural e a unidade nacional, sob o conceito de unidade na diversidade, mostrando a nova nacionalidade brasileira: uma cultura sincrética e democrata.

Segundo Chauí, a idéia de "identidade nacional" foi concebida em relação a uma alteridade, ou seja, a identidade do Brasil neste período correspondente a "questão nacional" se deu como um país subdesenvolvido, evocando a falta e a privação em relação aos países capitalistas desenvolvidos que seriam plenos e completos. Nesta mesma linha de raciocínio, tendo o Brasil como um país que terminados os anos correspondentes ao nacionalismo é tido como emergente, e ainda, frente a atual conjuntura, a idéia de nação ver-se-ia esmaecida, porém não foi o que aconteceu. Os fatos que explicam esse problema estão na esfera das tarefas político-ideológicas e segundo Chaú, a nação e o nacionalismo, a partir dos anos 80, serviriam para legitimar a nossa sociedade autoritária, oferecer mecanismos para a tolerância da violência e servir de parâmetros para conferencia de políticas de modernização do país. (Idem. p. 29)

Também é importante colocar aqui o fenômeno que Chauí denomina como verdeamarelismo, já que este colabora na fixação de um imaginário coletivo.

Podemos dizer que, segundo a autora, o verdeamarelismo foi construído no período referente ao princípio de nacionalidade e correspondia a imagem de um país essencialmente agrário que estava vinculado aos modos de produção capitalista de uma colônia de exploração. Tal imagem era celebrada pela classe dominante que pensava no progresso através de atividades que dependiam das riquezas da terra, exaltando a beleza da Natureza brasileira. Com o advento da industrialização e da urbanização, o verdeamarelismo ver-se-ia exaurido, porém não foi o que nos mostraram os fatos. A explicação para sua duração se dá pelo fato de num primeiro momento o fenômeno corresponder à imagem ideológica dos dominantes, enquanto sua conservação agiu como compensação imaginária à condição de atraso do país em um período - questão nacional - em que o Estado o promoveu. 
Assim, temos que durante o Estado Novo, contra a dispersão do poder e unificação do Estado, atitudes como a exaltação da bandeira e do hino nacionais foram promulgadas nas escolas; exigia-se que o enredo das escolas de samba tivessem temas nacionais; através dos meios de comunicação o Estado institui a Hora do Brasil, e ainda, através de discursos oficiais eram estimulados o gosto pelas artes populares, exaltavam-se os heróis e feitos do passado através do patriotismo; e por fim, os programas também deveriam exaltar a Natureza e as belezas do país. Sobretudo, o verdeamarelismo ainda prosperou passando da celebração da natureza, para a celebração do povo brasileiro, no momento em que o Estado necessitava incorporar em seu ideário a luta de classes concomitante a neutralização das ações políticas de tal, demonstrando um país sem problemas referentes ao capital e o trabalho, sob a direção de um Estado paternalista. Agiu também no governo desenvolvimentista demonstrando que o país era rico em recursos naturais, matéria-prima e energia barata de forma que pudesse assegurar seu próprio desenvolvimento com $\mathrm{o}$ mercado interno e contra o imperialismo. E, por fim, foi revitalizado nos anos da ditadura ou do Brasil Grande, agindo com uma ideologia geopolítica que teria território e qualidades suficientes para receber investimentos internacionais e grandes multinacionais. Assim, o fenômeno do verdeamarelismo só prosperou, pois as falas e as ações do Estado brasileiro se fundamentam de forma a manter viva a idéia de nação.

Por fim, na perspectiva da história da nação e do nacionalismo no Brasil, sob a ótica de Ortiz, em todas as épocas, a questão da identidade nacional é uma problemática que se atualiza, demonstrando-se sempre permeável aos questionamentos dos intelectuais. Através desses fatos retirados da história do nacional, fica claro como a questão da identidade nacional sempre esteve vinculada ao Estado. Nos contextos em que o poder estatal sofria algum tipo de transformação, como o Estado Novo, o golpe de 64 ou o regime militar, dentre outros, a questão da identidade nacional também necessitava de mudanças e uma nova ideologia era escrita, através dos intelectuais, com finalidade de definir o que era a "cara" do povo brasileiro segundo as bases do Estado.

Os símbolos que caracterizam a "cara" do Brasil estão presentes, como já dissemos anteriormente, nas obras do artista Nelson Leirner, e a necessidade de se compreender o diálogo que essas obras fazem com a identificação nacional ficou clara na posição do exministro de Estado da Cultura Francisco Weffort que, na apresentação do catálogo da exposição da 48. Biennale di Venezia, colocou a importância de se promover uma nova discussão sobre a cultura e a identidade do Brasil de hoje, visto que, os conceitos que davam conta da realidade cultural brasileira em 22 já não são mais aplicáveis no contexto da globalização. Desta forma, Nelson Leirner é preconizado, pois, suas obras documentam determinada fisionomia da cultura brasileira sob quaisquer rumos que a polêmica tome, e ainda, que Nelson Leirner vem demonstrar que continuamos sendo únicos e inconfundiveis, como sempre, de muitas e diferentes maneiras (WEFFORT in PEDROSA, 1999, p. 33).

O artista apresentou em 1984, no Museu de Arte Moderna do Rio de Janeiro, a obra $O$ Grande Desfile que era composta de centenas de objetos industrializados e artesanais retirados da cultura de massa, posteriormente tais objetos deram a origem à outra sucessão de obras, entre elas O Grande Combate (1985) e O Grande Enterro (1986). A Grande Missa (1994). Á partir desses trabalhos iniciais outras obras análogas a essas primeiras vêm sendo concebidas: Terra à Vista, em 1998 no Museu de Arte Contemporânea do Rio de Janeiro; $A$ Grande Parada, em 1999, na 48. Biennale di Venezia; uma versão de Futebol se apresentou em Brasília no ano de 2000, enquanto outra versão, com uma maior quantidade de elementos se apresentou em 2001 no SESC Pompéia em São Paulo; a partir de então cada vez que o 
grupo se apresenta ele toma outra composição, tendo os elementos re-arranjados, mantendo ou não o mesmo título.

Essas obras são instalações formadas a partir da apropriação de diversos objetos, artesanais ou industrializados (e esses últimos em sua grande maioria) retirados da cultura de massa, com características da estética kitsch, constituindo um grupo que se organiza em torno da situação que lhe atribui o nome. O que causa determinado estranhamento não se limita ao visual enquanto a união de objetos tão diversos, mas o significado que cada objeto possui e as relações semânticas que se desprendem de tais instalações.

Neste ponto convém colocarmos a seguinte questão, de que maneira tais objetos reunidos nas obras de Leirner, demonstram esta identidade? Ou ainda, por que tais objetos apontam características brasileiras? Para que essas questões possam ser respondidas, iremos desdobrar as obras buscando decompô-las.

A obra que deu início às sucessivas outras foi O Grande Desfile. Tal obra é composta por diversos objetos que são dispostos em uma fila seqüencial no espaço expositivo, organizados e montados de maneira que nos remete a ação de desfilar. Segundo o dicionário, o significado da palavra desfilar é marchar em fila; seguir-se imediatamente um após o outro; suceder-se (FERREIRA, 2001, p. 154). Temos neste caso um desfile, como nos desfiles carnavalescos, uma sucessão de fantasias alegóricas. $O$ índio se apresenta remetendo a figura nativa do país e, mais tarde, ao romantismo do indígena encarnado no bom selvagem; as imagens dos santos católicos representam a raça branca e européia, superior pelas teorias evolucionistas e deterministas; o negro vem representado pelas imagens do Umbanda, através dos pais-de-santo, Iemanjás e pretos velhos, aludindo a imagem de identidade do Brasil do fim do século XIX e início do século XX. O carnaval, implícito no próprio título da obra, nos faz lembrar o cotidiano e as celebrações do mestiço, que no começo do século foi o elemento identificador do país, bem como uma gama de outros objetos, visto que em tal período, tudo o que era popular enquadrava-se como nacional. Ainda podemos dizer que os brinquedos de guerra representam as lutas das classes sociais, que passaram a ser vistas como nacionais a partir do momento em que adveio um Estado vigilante e paternalista. E, por fim, as estátuas de animais e os sapos, rãs, aranhas e lagartixas, podem representar a fauna e os atributos que a Natureza presenteou o país, dadas pelo verdeamarelismo. Todos em suas fantasias alegóricas constituindo o mito da nação.

As outras obras que seguem são compostas pelos mesmos elementos e, portanto seguem conclusões parecidas, salvo a disposição deles que podem evocar leituras diferentes e alguns objetos que foram incluídos em obras mais recentes.

Em Terra à Vista, os mesmos objetos acrescidos de alguns outros, são expostos na nave do Museu de Arte contemporânea do Rio de Janeiro, todos voltados para a grande vidraça que mostra o Pão de Açúcar. Nesta obra, a união dos elementos que representam o Brasil convida o indivíduo fruidor a contemplar a verdadeira obra, aquela que está fora do museu, ou seja, a paisagem carioca. Não é à toa que o artista sempre utiliza elementos que já têm suas imagens tão gastas, diluídas a ponto de passar por nós desapercebidos, de forma que ao retira-los do cotidiano do brasileiro e leva-las às exposições engendre uma resignificação de tais objetos. Faz, assim, com que os fruidores desloquem também o sentido dos elementos, vivenciando suas trajetórias que vão desde os cantos das casas entre salas, cozinhas e quintais, as feiras livres e camelôs, até chegarem sob a imagem sacra dos museus e galerias. O mesmo processo ocorre com a paisagem carioca que, tendo virado símbolo da exaltação da geografia do Brasil, foi consumida em todos os âmbitos, desde a indústria do turismo às ideologias estatais, e o que o artista faz é mais uma vez um convite para uma re- 
significação dessa paisagem, de modo que os visitantes ao aceitarem a chamada passem a integrar o grupo que, pasmos com tamanha beleza, estão inertes reverenciando o ícone do Brasil.

Nas obras como Futebol (2000), Futebol (2001) e Maracanã (2003) além da identificação óbvia a qual o tema remete ainda encontramos recentes elementos que aludem, mais uma vez, ao verdeamarelismo de Chauí. As dezenas de coqueiros dispostas ao redor do campo de futebol demonstram o quanto ainda não podemos nos desvencilhar da imagem do país agrário, das belezas naturais e do Brasil lindo e trigueiro. Nossa atenção, ainda se volta para um outro novo elemento - os jogadores são gatos da sorte da cultura japonesa. Tais objetos, bem como, as imagens de Buda, nos indicam uma aculturação ocorrida meio a um país que amalgamou diversas culturas, sincretizou religiosidades após acolher os imigrantes estrangeiros.

O último elemento a ser aqui discorrido são as bandeiras do país que Leirner espalha por suas obras, além de serem muito utilizadas em outras obras do artista. A utilização do elemento bandeira tem forte indicação estatal, ela não é somente um elemento representativo utilizado pelo povo, mas um objeto cívico que transcende o simples material e preenche um campo semântico fortíssimo. Ao tomar posse de tais bandeirolas e coordena-las meio as obras, Nelson Leirner, tem uma atitude semelhante ao seu pensamento em relação à Arte - a dessacralização de estatutos. O significado ritualístico das bandeiras pode ser equiparado, com tal atitude, as dezenas de Mickeys Mouse que se encontram contíguas a essa, colocando todos os elementos ali presentes em um mesmo patamar de significação, ação não tão divergente das que vemos cotidianamente por toda parte das grandes cidades - a banalização de elementos sacros.

Fica claro que a identidade nacional encontrada na obra de Leirner se dá através de elementos referentes aos vários períodos constituintes da construção da nação brasileira nos quais, quase sempre, uma ideologia estatal, através de intelectuais, elegeu os papeis que representariam a nação. É desta forma, que elementos como a raça, o mulato, o samba, o carnaval, o futebol, as belezas naturais do país, o sincretismo religioso, a conscientização das massas frente ao colonialismo são, pelo artista, transmutados nos vários objetos já arrolados, unidos ao intenso colorido, de maneira que possam representar em uma única situação tudo que até hoje pôde ser visto como características do Brasil.

Tendo Nelson Leirner como uma artista que não só vivenciou como também participou ativamente do cenário pertencente à fase correspondente a "identidade nacional", tendo ainda que este sempre foi um artista crítico e irônico perante o sistema, podemos concluir que tais objetos foram por ele utilizados com o intuito de que a ironia deles advinda está para a falta de cabimento do papel dos nacionalismos na atual conjuntura e, assim como Chauí colocou, eles viriam legitimar a violência e o autoritarismo tal qual a própria idéia desses nacionalismos. Esses fatos ficam mais evidentes quando na obra O Grande Combate (1986) ele arrola os objetos representantes do país frente a uma batalha, na qual a autoridade e a violência são citadas plasticamente.

Ao utilizar-se de índices os elementos já consagrados no país como identificadores nacionais, Leirner, não só questiona tal situação, nos fazendo pensar sobre o quanto esses objetos estão presentes em nosso cotidiano e nem nos damos conta, como também acaba por perpetuar e reafirmar uma identidade nacional, não só dentro do país, como também no exterior, aumentando significativamente a "cara" do Brasil e a alteridade perante os outros países. 


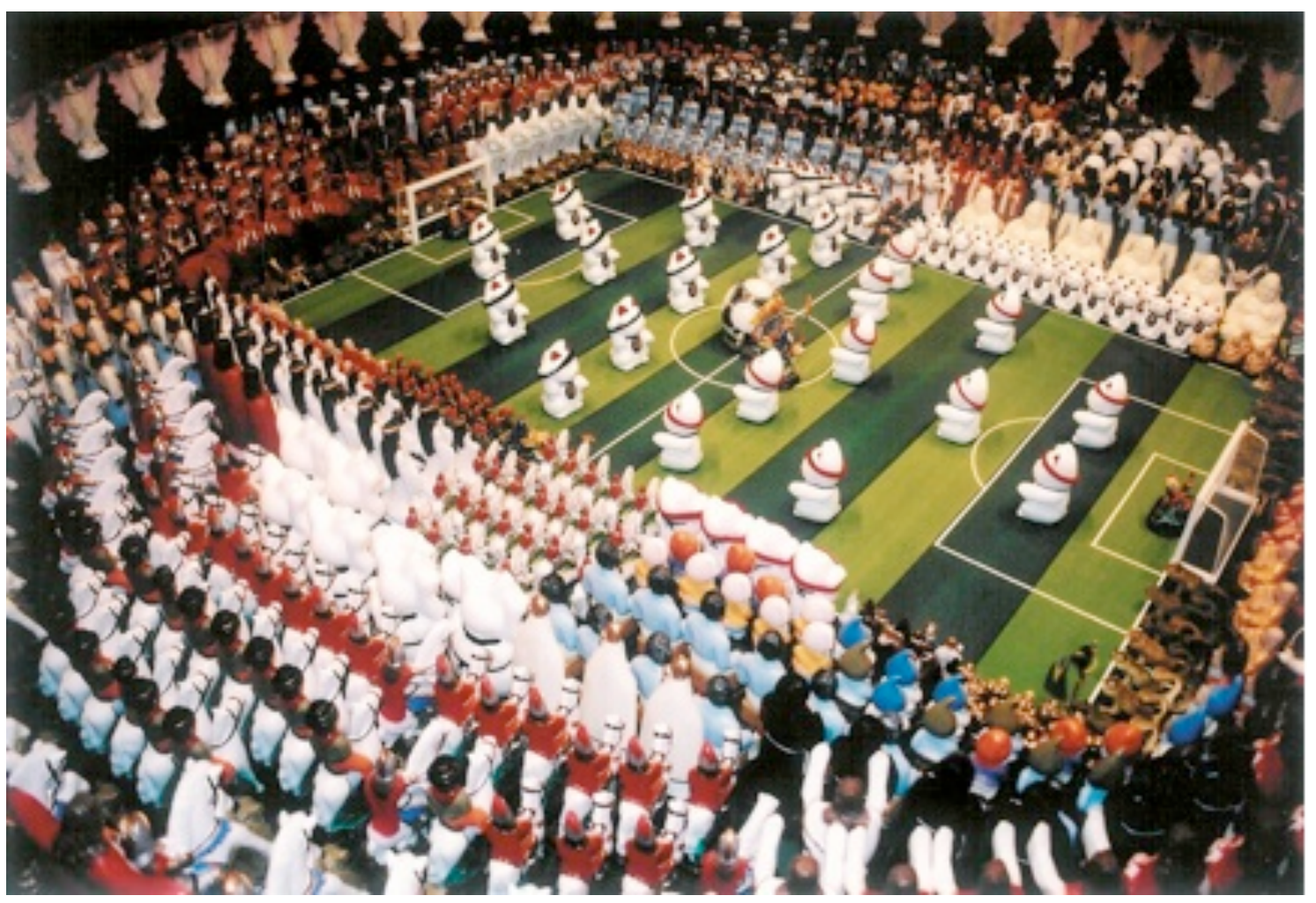

Maracanã, 2003

Gesso, cerâmica e plástico.

$120 "$ x $130 "$ x 9.5"

\section{Referências Bibliográficas}

CHAUÍ, Marilena. Brasil - mito fundador e sociedade autoritária.São Paulo: Fundação Perseu

Abramo, 2000.

CHIARELLI, Tadeu. Nelson Leirner: arte e não arte. São Paulo, Takano, 2002. CUCHE, Denis. A noção de cultura nas ciências sociais. Bauru: EDUSC, 2002.

FARIAS, Agnaldo. Nelson Leirner na Luisa Strina. In Guia das Artes São Paulo. São Paulo, 1991.

Nelson Leirner. São Paulo: Secretaria do Estado da Cultura, 1994. Nelson Leirner. São Paulo: Centro Cultural Light., 1997.

FERREIRA, Aurélio B. de Holanda. Minidicionário da Língua Portuguesa. Rio de Janeiro: Nova Fronteira, 2000.

GONÇALVES, Lisbeth R. As identidades culturais e a comunicação. In: Revista Arte e Cultura da América Latina. Vol. XIII. São Paulo: Terceira Margem, 2004.

ORTIZ, Renato. Mundialização e cultura. São Paulo: Brasiliense, 2000. Cultura brasileira \& identidade nacional. São Paulo: Brasiliense, 1985.

PEDROSA, Adriano (org.) Nelson Leirner e Iran do Espírito Santo. 48. Biennale di Venezia - Padiglione Brasile. São Paulo: Fundação Bienal de São Paulo, 1999. 